\title{
What is the Influence of News Media on People's Perception of Corruption? Parametric and Non-Parametric Approaches
}

\author{
Nicholas Charron ${ }^{1}$ (D) Paola Annoni ${ }^{2}$ \\ Accepted: 18 October 2020 / Published online: 8 November 2020 \\ (c) The Author(s) 2020
}

\begin{abstract}
Does the source of one's news media have a systematic effect on one's perception of political corruption? While numerous studies have investigated the extent to which media affects trust in institutions, or the polarization of political values, this study shifts the focus on to how one's media source conceived here as social media versus traditional media affects the perception of corruption in 2 ways. First, we hypothesize that citizens who consume their news predominately from social media will have higher perceptions of political corruption than consumers of more traditional media sources. Second, we hypothesize that perceptions among social media consumers will be more polarized. Specifically, we argue that the gap in corruption perception between supporters of government and opposition political parties will be larger among social media consumers compared to traditional news consumers. We test our hypotheses using newly collected survey data from the European Quality of Government Index survey from 2017, which contains nearly 78,000 respondents in 21 countries in the European Union. Estimating our model with both parametric and non-parametric approaches, we find robust empirical support for two of our 3 hypotheses.
\end{abstract}

Keywords Social media $\cdot$ Corruption perceptions $\cdot$ Decision trees $\cdot$ Non-parametric estimation · European regions

\section{Introduction}

The pronounced loss of trust and perceived malfeasance in public institutions, accompanied by the polarization of citizen values, poses a core challenge to many of today's Western democracies (Abramowitz and Sanders 2008; Ingelhart and Welzel 2010; Fukayama 2018). While the causes put forward to explain these phenomena are many, from rising inequality to immigration and technological change, this paper investigates how media affect citizens perceptions of corruption in European democracies. Specifically, 2 related research

Nicholas Charron

Nicholas.charron@pol.gu.se

Paola Annoni

Paola.annoni@ec.europa.eu

1 University of Gothenburg, Sprängkulsgatan 19, 41005 Göteborg, Sweden

2 European Commission, Directorate General for Regional and Urban Policy, Brussels, Belgium 
questions are posed. One, does the source of one's news systematically affect perceptions of corruption? And 2, are certain sources more likely to polarize perceptions of corruption more than others? And if so, why?

In this study, we compare 2 broad groups of media source, defined here as 'traditional media' such as professional radio, television, newspapers versus 'social media' such as YouTube, blogs, Facebook or Twitter. As the use of social media has increased among citizens over time, many scholars have sought to better understand how this affects citizens' political attitudes and behavior. On the one hand, there are those that investigate the degree to which various types of media sources (such as social media) affect the level of trust in political institutions (Nie 2001; Valenzuela et al. 2009; Norris 2011; Gil de Zuniga et al. 2012; Aarts et al. 2012). While the mechanisms are still under debate, many studies have shown that consumers of less traditional sources also tend to show less trust on average.

On the other hand, there are numerous studies that investigate the effects of social media on the polarization of citizen values, mainly on the level and moderation/extremism of views on political matters, or citizens' self-placement on left-right scales. While several influential studies have found that such media platforms lead to more polarization (Conover et al. 2012; Hindman 2009), other recent empirical evidence provided by Barbera (2015) demonstrates the opposite. Thus, there is a debate concerning this relationship.

Our paper merges findings from a number of contemporary literatures and offers several contributions. First, on neither of these 2 questions (1) how media influences the overall assessment of government by citizens, and (2) the extent to which certain media sources polarize citizens' attitudes have previous studies analyzed perceptions of corruption of political institutions. We do so by creating a composite index of a battery of questions concerning perceptions of corruption on the latest European Quality of Government Index survey, fielded in 2017 (Charron et al. 2019). We explore the link between media consumption sources and perceptions of corruption in a comparative setting with nearly 78,000 respondents in 21 European democracies. The survey has been improved with respect to the first 2 editions by a thorough statistical analysis (Annoni and Charron 2019) and includes for the first time a question about media consumption and the sources one most often turns to for news. While our research design is cross-sectional and thus does not allow us to examine the effects of these media platforms over time, it does allow us to compare the perceptions and views of social media consumers with people who obtain news from other types of sources across multiple countries. How the source of one's media might (or might not) affect the level of corruption perception and the extent to which these perceptions are more or less polarized among the public is the central line of investigation in this study.

In addition, we contribute to an ongoing debate about the extent to which factors other than corruption drive citizens perceptions of corruption in surveys (Mishler and Rose 2008; Olken 2009; Sharafutdinova 2010; Donchev and Ujhelyi 2014; Charron 2016). While some studies have looked at the effects of media on corruption from a macro perspective the level of press freedom in a country for example (Lindstadt and Naurin 2010) none, to our knowledge, have compared levels and/or dispersions of corruption perception as a function of one's source of media at the micro-level. Given the established link between corruption perceptions and overall trust in political institutions and democratic satisfaction (Pellegata and Memoli 2016; Maciel, and de Sousa 2018), this is a highly policy-relevant topic. Moreover, our findings have potential implications for the validity of corruption measures based on citizen perceptions.

Finally, in investigating how various media affects polarization of corruption perceptions, this allows us to shift from left-right ideological self-placement (Iverson and Soskice 2015), and focus on more straight-forward opinions about the nature of the political 
institutions in one's country whether political leaders are perceived to be serving the interests of the general public or serving only the powerful. The more people view their institutions as corrupt, the more likely they are either to support radical populist challengers (Agerberg 2017) or abstain from politics altogether (Bauhr and Charron 2018).

In estimating the effects of media on corruption perceptions, we employ innovative nonparametric statistical approaches and more classical parametric approaches as well. With respect to non-parametric modelling, we report results from Multivariate Adaptive Regression Splines (MARS) to analyse in a more robust way the non-linear and interaction effects among the many variable in the model, which can be problematic for more standard estimation methods such as linear regression, in particular with micro level data with a large sample size. In addition, we report estimates from ordered logistic regression as well as simple bivariate differences of means and variances.

We find that our measures of corruption perception are, on average, higher among social media users compared with people who mainly obtain news from other sources. In addition, we also find that perceptions of corruption are more dispersed (polarized) among social media consumers. In particular, the gap in corruption perception between supporters of sitting government parties versus those that support opposition parties is wider among social media users than those who consume news via other mediums.

The remainder of the paper is organized as follows. First, we address the relevant literatures to which this paper seeks to contribute followed by our theoretical contribution. Next, the data, sample and design of the study are presented, followed by the results of the tests of 3 empirical hypotheses. The paper concludes with a discussion of the main findings and offers points of departure for future research.

\section{How Does Media Source Affect Corruption Perceptions?}

The relationship between media, broadly speaking, and citizens' assessment of their political institutions, in the form of trust or perceptions of corruption, remains under debate. At the country level, many scholars point to the positive relationship between the level of press freedom and a more positive assessment of institutions in the form of lower perceptions of political corruption (Brunetti and Weder 2003; Freille et al 2007; Lindstadt and Naurin 2010).

Yet these inferences give us only the 'birds-eye' picture, and overlook the significant heterogeneity of individual perceptions within countries between and among various groups. There is, however, a literature that investigates that which in fact affects corruption perceptions other than corruption (Heywood and Rose 2014). The literature on this topic is largely concerned with factors that explain perceptions of corruption other than direct personal experience (Olken 2009; Rose and Mishler 2007). In general, such studies have largely found that individual perceptions of corruption are in fact systematically driven by outside factors such as individual level demographics (age, gender, education, position in labor market, etc.), or contextual factors such as the size of the country, the level of development or level of democracy (Donchev and Ujhelyi 2014).

One factor about which the literature is unclear, is regarding the effect of media on corruption perceptions at the micro level. Several comparative studies on the perception of corruption include a measure of press freedom. This is often captured as a macro-level variable in multi-level analyses (Mishler and Rose 2008; Sharafutdinova 2010; Donchev and Ujhelyi 2014; Charron 2016). Others look at media in relation to citizen responses 
to political corruption (Ferraz and Finan 2008; Costas-Pérez et al 2012) or how internet searches for corruption or internet availability correlate with perceptions and incidences of corruption across countries (Anderson et al. 2011; Goel et al 2012). However, people do not consume media in a monolithic way media consumption across individuals comes from heterogeneous sources and mediums, which can have divergent effects on citizen perception of corruption at the individual level. Thus, there is a clear gap in the literature on how individual choice of media consumption affects evaluation of public institutions.

Building on a longstanding literature from political science and social phycology on how media affect political opinions and behavior (Prior 2013; Valkenburg et al 2016), this study fills this gap and develops a theoretical argument that the source of one's news systematically affects corruption perceptions. In doing so, we focus primarily on the division between 'traditional' (professional TV, radio and newspapers) and 'social media' sources (YouTube, blogs, Facebook, Twitter, etc.) and how this division affects perceptions of corruption in two ways. First, the primary medium through which one acquires news is likely to affect the overall level of perceived corruption in society. Second, the different mediums through which one consumes news are likely to lead to varying levels of polarization of opinion. The mechanisms of each effect are explained below.

\subsection{Effect 1: Media Source and Corruption Perceptions}

For decades, scholars have debated the link between an individual's political attitudes and behaviors and the media source from which one acquires information. For example, in Putnam's (1995) widely cited work on declining social capital in the U.S., he cites television as a primary cause, while others rejected this claim (Norris 2000). More recently, scholars have moved to investigate whether the acquisition of news from more traditional sources and news from social media can explain variation in citizens' level of trust and social capital (Nie 2001; Valenzuela et al 2009; Gil de Zuniga et al. 2012; Aarts et al 2012). For example, Ceron (2015) shows in a cross-country analysis of European states that political trust is considerably higher among people who acquire news from more traditional news sources than consumers of newer social media sources (such as blogs, YouTube, Facebook or Twitter, etc.). Norris (2011) finds that compared with people who consume news from more traditional sources such as newspapers or radio, internet use (broadly) as a media source is associated with lower levels of democratic satisfaction among respondents. Other studies find systematic differences in social media and offline political participation (Oser et al 2013), which also suggests variation in trust levels based on social media consumption.

While all media provide citizens with information that can be used to assess their political institutions, varying sources of news have different incentives on how to angle such information (Norris 2011). With this in mind, the key mechanism that the literature on media and political trust often puts forward is the distinction in the amount of influence from the political and economic elites in a country (e.g. 'gatekeepers'). Traditional sources are more strongly controlled by gatekeeping elites, while social media are much less so, with many sources controlled by outsiders (Hindman 2009; Ananny 2014). Elites are assumed to be generally in favor of the status quo, while outsiders can vary from considerably more critical, to overly fawning of the political establishment. Broadly speaking, the presentation of news from more traditional sources is expected to provide information that is more favorable (less critical) to those in power (Hermida et al 2014). Editorial filtering will generally tone down those topics of political corruption that counter the interests of the elite political class (Lewis 2012). On the other hand, information coming from newer 
media, less under the control of political and economic elites, is presented without such considerations, and can challenge the agenda setting power of the traditional gatekeepers (Feezell 2018), oftentimes in a more sensational way (e.g. 'click bait'). For example, Facebook was recently accused of failing to tackle misleading and incorrect internet content that was lacking in editorial oversight. As a response, Facebook "pledged to verify the identities of administrators of popular Facebook pages and advertisers buying political issue ads on debated topic of national legislative importance such as education, immigration and abortion" (The Guardian, May 3rd 2018). However, loosely controlled social media can be substantially more critical, and thus negatively influence perceptions of political institutions, which serves as a mechanism to increased perceptions of corruption and decline in trust among such consumers. Evidence for this effect is even found in authoritarian China, where Zhu et al. (2015) show that citizens who mainly get news from state run (traditional) newspapers have significantly lower perceptions of government corruption than those who acquire information from 'Grapevine' (non-traditional) news sources.

While the question of the effect of media source on corruption perceptions is empirical and untested, we would expect similar dynamics as those affecting political trust and democratic satisfaction from the findings in the literature. The assumption to be tested is whether those who primarily consume news from less traditional, social media sources will have higher levels of perceived corruption than do consumers of traditional sources, which leads us to our first hypothesis:

Hypothesis $\mathrm{H} 1$ Compared with consumers of traditional media, corruption perception will be higher among those who get news primarily from social media, ceteris paribus.

\subsubsection{Effect 2: Media Source and Polarization of Institutional Assessments}

The second effect of media source on corruption perceptions is on the distribution of opinion between groups that receive news from different sources e.g. what is often referred to as 'polarization' on the topic. In recent decades, a substantial literature has investigated how various media affect the polarization of opinions among people, with an overwhelming amount of research on this topic focusing on polarization of political views in the US. The main crux of the discussion is whether certain types of media facilitate Balkanization of like-minded people, or rather expose people to diverse opinions and ideas. A central hypothesis from this literature is that sources that expose consumers to more (less) likeminded ideas and opinions, whatever these opinions may be, are likely to facilitate more (less) polarization of opinions (Huckfeldt and Sprague 1995; Mutz 2001; Conover et al 2011).

For our purposes, we posit that the relationship between media source and perceptions of corruption is a function of the supply and demand of the market. On the demand side, it is assumed that citizens will generally seek information about that which they are interested and which corresponds in large part to their political leanings; in other words 'selective exposure' (Nie et al 2010; Valkenurg et al. 2016). While this does not apply in all cases, on average there is strong empirical support from social phycology that citizens seek such news information, all things being equal (Bennett and Iyengar 2008). The demand side of this theory is an untested assumption of the theoretical model in this study.

The supply side of the equation concerns the source of the news and the extent to which political opinions, content and ideas vary. This side of the model is assumed to be economically rational in that there are clear cost-benefit calculations made by various suppliers 
of news media. The key assumption is that supply is a function of 'barrier to entry' costs. When barrier to entry costs are high, this implies that there are fewer competitors in the marketplace providing news and that such competitors need a large audience in order to make their business models successful (Baum 2003; Prior 2007; Nie et al 2010). For example, Campante and Hojman (2013) show in their historical analysis of the introduction of TV in the US media news landscape that polarization among the US public decreased as TV (with only a few channels at the time) became a more ubiquitous source of news among Americans. Conversely, when barrier to entry costs are low, there are more competitors; and such providers need fewer consumers to make a profit. In this environment, there is thus a greater incentive to attract niche audiences, which creates more heterogeneity of news content (Baum 2003).

In the case of the news sources investigated here traditional (professional radio, television, traditional newspaper; online or print) and social media social media clearly offers the lowest barrier to entry. With political blogs, twitter, Facebook and YouTube posts for example offering a wide diversification of opinions and content at a fraction of the cost of more traditional sources, this allows citizens to much more closely match their pre-existing beliefs with their news; e.g. the demand side is more closely matched with supply. In this case, we then expect the corruption perceptions of people who mainly consume news on social media to be more polarized (more heterogeneously distributed) than the perceptions of people who obtain their news from sources with higher barriers to entry, e.g. traditional professional sources.

It is worth noting, however, that some offer the opposing view that consuming social media in fact reduces mass polarization of views. For example, Barbera (2015) finds that people become exposed to a greater diversity of opinions via social media consumption over time. While such studies are impressive in their data collection and analysis of Twitter users over time, the reference ('counterfactual') group in such studies is people who consume less social media, not necessarily those who elect to most often acquire their news from other types of sources. It thus remains an open empirical question as to whether social media is associated with greater levels of opinion polarization among citizens.

Most studies of media effects focus on polarization of political values mainly in the US context, with issues such as same-sex marriage, abortion, taxes, etc. However, evaluations of the political system as a whole are highly salient in explaining a wide array of behavior, from voting to trust in the political system (Kostadinova 2009; Dahlberg and Solivid 2016; Bauhr and Charron 2018). Moreover, as the US has received the bulk of the focus of this literature, many European states have gone under-researched. In order to fill this gap, the levels of corruption perception and the extent to which such perceptions are polarized as a function of news source is investigated here, using newly collected survey data in $21 \mathrm{EU}$ countries. Using this design, this second hypothesis is tested:

Hypothesis H2 Compared with consumers of traditional media, corruption perceptions will be more polarized among those that get news from social media, ceteris paribus.

While $\mathrm{H} 2$ posits about the degree of polarization in general, we inquire one-step further in our final hypothesis around which cleavages are people's views polarized? Building on the literature of partisan perceptual biases (for example, Campbell et al. 1960; Bartels 2002), we anticipate that the gap in perceptions of corruption between partisan government supporters and opposition supporters will be wider among social media followers than among traditional media consumers. The empirical literature shows that partisans tend to 
latch on to positive news about their favored party, while selectively filtering out or rejecting negative information (Jerit and Barabas 2012). With respect to corruption specifically, several studies have found that partisan supporters of the sitting government perceive lower corruption on average compared with opposition voters or non-partisans (Anderson and Tverdova 2003; Blais et al. 2017; Agerberg 2020), or that they tend to be willing to overlook corruption scandals in their own party in elections (Anduiza et al. 2013; Charron and Bågenholm 2016).

Yet to our knowledge, no study to date has looked at the interaction between partisanship and one's main source of news. As consumers of social media are most likely to come across favorable (unfavorable) news stories to supporters of the government (opposition), we anticipate that the gap in perceptions among these two groups will be greatest among social media users, compared with government and opposition supporters who mainly consume news from other sources. Our anticipation is thus that the partisan gap in corruption perceptions will be amplified among social media followers. The following, last hypothesis is thus tested:

Hypothesis H3 The gap in corruption perceptions among supporters of government and opposition parties is likely to be larger among social media consumers than traditional ones, ceteris paribus.

\subsubsection{Data and Design}

This study relies on newly collected data from the third round of the Quality of Government Institute's 'European Quality of Government Index' (EQI) survey (Charron et al. 2019). The survey's primary aim is to build regional indices of quality of government and facilitate multi-level research on governance in EU countries (Charron et al. 2015). The questions capture the extent to which citizens experience and perceive corruption within their local and regional public services and feel that their services are of good quality, are treated fairly by local public servants and that services are allocated impartiality to all citizens. The sample is made up of residents of 18 years of age or older, who were contacted randomly via telephone in the local language. Telephone interviews were conducted via both landlines and mobile phones, with both methods being used in most countries. In all, 77,966 respondents were included in 21 EU countries and the survey design selected respondents within 185 regions in these countries, such that design weights are used in all analyses to account for this (see "Appendix Sect. 2" for more details on the survey).

The survey includes several questions on perceptions of corruption that are of interest here and serve as dependent variables in the analyses. While several questions inquire about specific services, such as education or health care, we elect to focus on perceptions or institutions more broadly. ${ }^{1}$ The 2 most suitable questions to test our theory are those that pertain to various types of general, societal corruption:

People in my area must use some form of corruption just to get some basic public services.

Corruption in my area is used to get access to special unfair privileges and wealth.

\footnotetext{
${ }^{1}$ However, we check the robustness of our findings using an aggregate index of the 5 corruption items in “Appendix Sect. 4, Tables 8 and 9".
} 


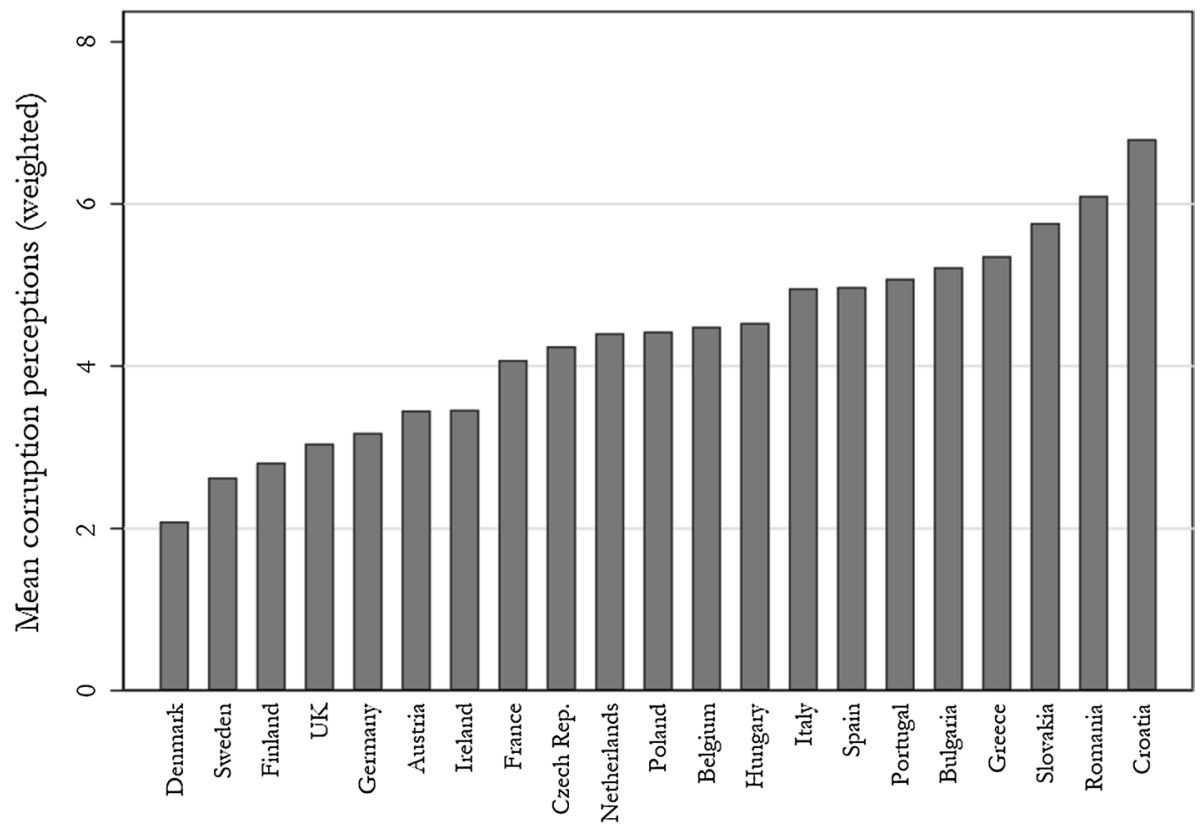

Fig. 1 Citizen perceptions corruption in 21 EU countries. Note: weighted country means reported

From these survey items, we create a simple additive index. ${ }^{2}$ Distributions by country, which are sorted from the lowest (Denmark) to the highest (Croatia) are shown in Fig. 1.

The main independent variables are taken from a newly included survey question item in the 2017 survey, which pertains to the media, where the order of the alternatives was randomized.

From which of the following do you most often get your news?

a. in a print or online newspaper, b. on the radio, c. on television, d. a social networking site (such as Facebook or Twitter), e. don't know.

Of course, this question has its strengths and weaknesses in testing the main hypotheses of interest. First, the question, along with the spatial design itself, limits the ability to test causal direction e.g. whether respondents who already had higher or lower levels of corruption perception seek out certain types of media sources. We do not know the amount of time spent acquiring news information from these sources, or even what these sources are. For example, a UK reader of newspapers might only read the Guardian or the Daily Mail, and they may be a passive or active consumer, which itself might have consequences for their perception on many issues including corruption. It would also be relevant to know the degree to which consumers of social media consider news links shared from friends, opinion pundits, or political leaders. Finally, we also do not have information on the extent to which people to choose multiple media sources and the approximate percentage of time

\footnotetext{
${ }^{2}$ Cronbach's alpha coefficient is 0.80 for the 2 -items, and a principle component factor analysis shows that they load onto a single factor (Eigenvalue $=1.63$, proportion variance explained $=0.83$ ), thus implying that the items are capturing a single latent concept.
} 
Table 1 Test for difference in means and variances of corruption perception by media source

\begin{tabular}{llll}
\hline & $\begin{array}{l}\text { Traditional } \\
\text { media }\end{array}$ & Social media & Difference $(p$-value $)$ \\
\hline Mean & 4.31 & 4.73 & $0.42(0.000)$ \\
Variance & 7.17 & 7.60 & $0.43(0.000)$ \\
\hline
\end{tabular}

Sample-wise unweighted averages, $p$-values report one-tailed tests

spent consuming from each source, as many people most likely do in their daily lives; instead they are asked to choose the one on which they mostly rely.

However, this also serves as an advantage the comparison across groups is much cleaner. It distinguishes between types of online content, in what some refer to as 'web 1.0' (traditional online news sources) and 'web 2.0' (social media, blogs, etc.) (O'Reilly 2005). And, as opposed to studies looking at only the effects of social media on various political opinions, this question offers a clear reference group with which we can compare the social media category to other media sources. In sum, while certainly not perfect, the measure gives us some indication of media source and allows us to engage in a discussion about how media sources and corruption perceptions are related in a comparative framework. The sample-wide, weighted distribution of the variable is: print/online traditional newspapers $(21.5 \%)$, radio $(13.5 \%)$, TV $(41.4 \%)$, social media (23.3\%), don't know (0.3\%). For the purposes of the main analysis and parsimonious comparison, we collapse the traditional sources (radio, TV and professional newspapers) to compare directly with the social media category.

Other control variables account for what previous studies have shown to be important in explaining individuals' perceptions of corruption, and which could confound the relationship between media choice and corruption. First, socio-economic status, such as income and education, has consistently been shown to be important; a dummy for university education or higher and an ordered variable for income are included. Residence of population, as more rural citizens might have less access to social media in some places. We account for political values representing left-right and Gal-tan dimensions, which could confound the main relationships, in particular at the extreme ends. These are accounted for with questions pertaining for example to preferences for income redistribution and immigration included in the 2017 survey (see the Appendix). We also check some models for the party family one supports as well to account for political leanings. Unemployment and retrospective opinions on the economy are included as well. Finally, age and gender are included in all models.

Figure 1 shows that there is relevant country-level variance in perceptions of corruption, thus fixed effects are included to account for unobserved country level factors. In all cases, sample and design weights are included. We estimate the models using both parametric and non-parametric statistical modelling.

\section{Results: Bivariate Analyses}

We begin with a simple bivariate overview of the main relationship in question in Table 1, which shows the association between respondents' main media news source and the two indicators of corruption perception. On the left hand side, we report the difference of means between social and traditional media consumers, whereby higher means (weighted) 
Table 2 Testing H1: determinants of corruption perception

\begin{tabular}{ll}
\hline Variable & $\begin{array}{l}\text { Relative } \\
\text { impor- } \\
\text { tance }\end{array}$ \\
\hline Country group & 100 \\
Satisfaction with the economy & 75.44 \\
Prefer strong leader & 17.35 \\
Oppose redistribution & 9.48 \\
Education level & 8.12 \\
Oppose immigration & 7.63 \\
Prefer market over state & 5.25 \\
Media effect & 4.52 \\
Economic growth over environment & 2.23 \\
Income level & 1.46 \\
\hline
\end{tabular}

equal higher levels of perceive corruption. We observe in all cases that the group of respondents who claim social media as their main news source has, on average, higher levels of perceived corruption. Pairwise difference of means $t$-tests (one tailed) show that the differences in the social media group are significantly higher than the traditional source group, showing initial bivariate support for $\mathrm{H} 1$.

Next, $\mathrm{H} 2$ expects that when making a comparison, perceptions of corruption will be the more polarized within the social media group compared with the traditional source group. In this sense, we refer to groups as having more or less 'dispersed' perceptions (see DiMaggio et al 1996). For the sake of parsimony in the bivariate analysis, we present the variance of the perceptions of corruption within each group as a straightforward metric to compare this idea across our groups in the right hand columns in Table 1. Again, in all cases, the social media group exhibits higher variance and it is confirmed that the differences are significantly different from the other media groups via a variance comparison test, the $F$-test. ${ }^{3}$

Yet 'polarization' is a multi-dimensional concept and one that has no agreed upon measure (DiMaggio et al. 1996). Thus, to compliment the $F$-test of corruption level variances, we compute 2 diversity indexes, we also provide the Gini index $G$ and the Shannon index $H$ (Landenna 1994; Morris et al 2014), originally used in biology and ecology for the analysis of biodiversity in species. ${ }^{4} G$ and $H$ (Table 2 ) are descriptive statistics measuring the level of diversity, namely dispersion, for categorical/ordinal variables as our dependent variable, namely the level of corruption perception. We use them to assess the dispersion of corruption perception across its 1-10 measurement contrasting the use to social media with the rest of media type.

\footnotetext{
${ }^{3}$ The test is an $F$-test comparing the standard deviations (s) of one group over another, which is given by: $F=\frac{s_{x}^{2}}{s_{y}^{2}}$ with $n_{x}-1$ and $n_{y}-1$ degrees of freedom.

${ }^{4}$ The normalized Gini index is calculated as: $\tilde{G}_{m}=\frac{\sum_{i=1}^{k} p_{i}\left(1-p_{i}\right)}{\frac{k-1}{k}}$ and normalized the Shannon index is computed as: $\tilde{H}_{m}=\frac{-\sum_{i=1}^{k} p_{i} \log \left(p_{i}\right)}{\log (k)}$ where, $m=$ type of media used (other or social), $k=$ number of different corruption categories ( $1=$ lowest perceived corruption; 10 highest perceived corruption), $p_{i}=$ the percentage of people scoring corruption category $i$.
} 

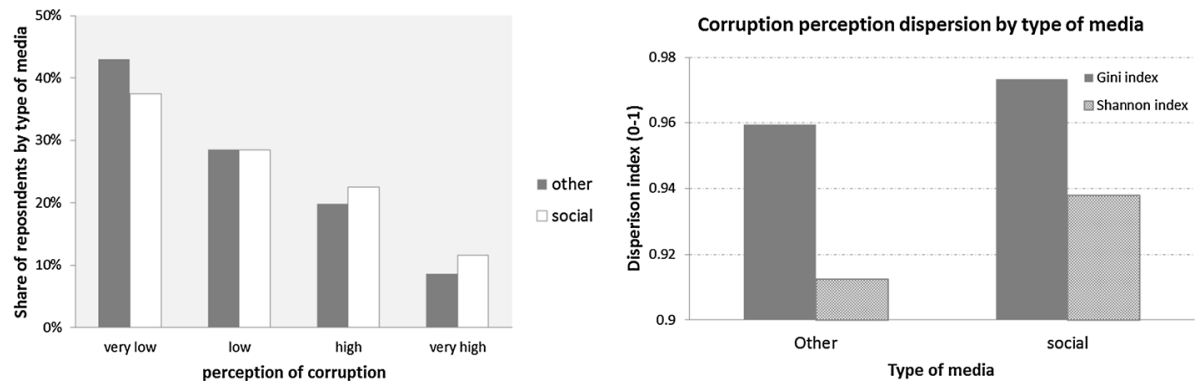

Fig. 2 Distribution of corruption perception levels among people using different types of media and normalized Gini and Shannon by type of media. Note: Left-hand side: share of respondents in different corruption perception categories by type of media (very low $=\leq 3$; low $=$ between 3 and 5.5; high $=$ between 6 and 8 ; very high $\geq 8$ ). Right-hand side: Normalised dispersion indexes (Gini and Shannon) of corruption perception, higher values correspond to greater levels of dispersion

In the theoretical situation where all the people perceive the same level of corruption the values of $G$ and $H$ are equal to 0 . The opposite situation is instead when people's perceptions are equally spread across of the levels of corruption. In this case $\mathrm{G}$ and $\mathrm{H}$ assume their maximum value. If our hypothesis holds, we expect to observe higher values of $G$ and $H$ for people using social media compared to more traditional media. As shown in Fig. 2, the hypothesis seems to be corroborated. The distribution of perceived corruption levels is more evenly spread among social media than other media users (Fig. 2, left-hand side) and $G$ and $H$ indexes are always greater for social media group than for the other group (Fig. 2, right-hand side).

\subsection{Multivariate Modelling for Testing H1 and H2: Non-Parametric Modelling}

While Table 1 and Fig. 2 demonstrate some initial support for $\mathrm{H} 1$ and $\mathrm{H} 2$, the relationship could plausibly be spurious and driven by several potentially confounding factors. To test the robustness of the bi-variate analysis when controlling for other individual factors, the decision-tree technique Multivariate Adaptive Regression Splines (MARS) is employed (Friedman 1991; De Veaux et al 1993). MARS is based on decision-tree techniques that we employ here for their ability to address data complexities, namely non-linearity and interaction effects, which often characterize empirical datasets in different fields and which are a challenge for more traditional statistical methods like linear regression (Deichmann et al 2002; Annoni and Catalina-Rubianes 2016; Zhang and Goh 2016). As opposed to linear regression, MARS is highly flexible and makes no assumptions about the underlying functional relationships between the dependent and independent variables. Similar to neural networks, MARS learns from data and, consequently, does not require any imposed linkfunction between the dependent variable and the predictors. In addition, MARS belongs to the family of machine-learning techniques for data mining, thus requiring 'big data' (Varian 2014). Our sample provides the ideal situation for using a statistical technique like MARS as our data is rather big (nearly 78,000 observations). Section 1 in the Appendix provides more details on MARS modelling.

MARS analysis is employed to test whether social media has an independent, positive effect on corruption perceptions (hypothesis H1). The effect of media is assessed while controlling for the country group effect, with groups defined as quartiles of the national 
GDP per capita, individual level factors such as standard socio-demographic controls (gender, age, education level, living in urban/rural areas, employment and income level), the perception of the state of the economy and other more policy-related variables indicating the individual's attitude towards private versus state ownership, income redistribution and inequality, immigration, environmental protection and strong leadership.

As the first step of MARS analysis, we tested if higher order interaction models significantly improve the goodness-of-fit of the simpler additive model. Second and thirdorder models are used to verify whether interactions between the different explanatory factors-type of media and the other covariates play a significant role in explaining corruption perception levels. We find that both higher-order models outperform the additive model but only marginally, with a goodness-of-fit 2.2 and $2.3 \%$ higher respectively. ${ }^{5}$ Interaction effects can therefore be considered as negligible and the simpler additive model is chosen to test hypothesis $\mathrm{H} 1$.

In Table 2 predictors are ranked according to their contribution in explaining corruption perception variability. Apart from the country group effect, indicating the country level of development as the most important driver of corruption perception, political attitudes, education level and use of social media are all important factors.

Figures 3 shows the estimated optimal type of relationship, called Basis Function $B F$ in MARS, between each predictor and the dependent variable. ${ }^{6}$ In case of discrete predictors, the $B F$ shows the relative effect (y-axis) across the different levels of the predictor (x-axis) on the dependent variable. As noted, MARS does not assume linearity as does classical regression, and thus while we observe that in some cases an approximate linear relationship such as economic satisfaction in other cases, the relationship is non-linear, such as the 'market-state' variable. Results reveal that corruption perception is higher in poorer countries (Fig. 3a) and for lowly educated people (Fig. 3e). Even if not among the most important drivers, the marginal effect of social media is higher than that of other media (Fig. 3h, thus supporting hypothesis H1.

As for the effects of the remaining control variables, they are largely in the direction expected by the literature. Satisfaction with the state of the economy (Fig. 3b), which has the strongest effect at the individual level second to the country effect only, is a significant predictor in the expected direction: people who are more optimistic about the state of the economy tend to complain less about corruption levels. Political value items have in general a significant effect on the dependent variables with almost regular, step-wise linear trends. We observe that respondents who lean to the right on issues about strong leadership, income redistribution, immigration and economic markets report a higher of corruption perception (Fig. 3c, d, f and g). Finally, individuals with a strong position about prioritizing economic growth over environmental protection or vice-versa have, on average, a higher perception of corruption (Fig. 3i).

Moving to hypothesis $\mathrm{H} 2$, we observed that the variance and dispersion tests discussed above (Table 1 and Fig. 2) indicate a greater dispersion of corruption perception among those who preferably use social rather than traditional media, indicating some initial support for the hypothesis. Does this finding hold when including controlling factors?

\footnotetext{
5 See Table 3 in the Appendix for the results of the goodness of fit tests.

6 Basis Functions are estimated in MARS through a data-driven algorithm to optimally predict the dependent variable (see the Appendix for further explanation on $B F \mathrm{~s}$ ).
} 


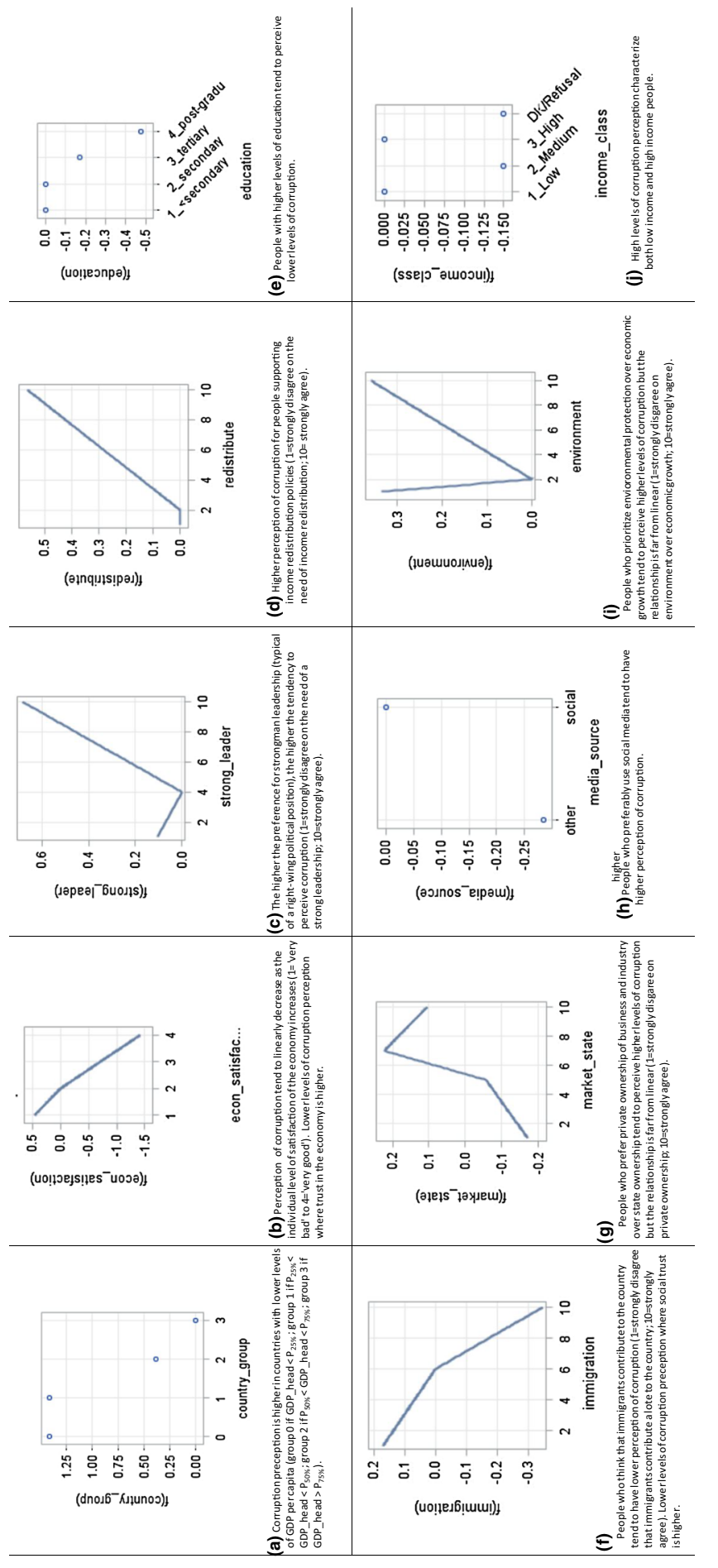


Table 3 Comparison of the goodness-of-fit of higher-order interaction MARS models
Table 4 Testing H2:

determinants of corruption perception polarization
Goodness-of-fit improvement

2nd order versus 3 rd order additive model versus additive model

\begin{tabular}{lll} 
MARS model testing $H 1$ & $2.2 \%$ & $2.3 \%$ \\
MARS model testing $H 2$ & $1.3 \%$ & $2.5 \%$ \\
\hline
\end{tabular}

Interpretation for the modelling testing $\mathrm{H} 1$ : the 2 nd order interaction model has a goodness-of-fit only $2.19 \%$ higher than the additive model; whilst the goodness-of-fit of the $3^{\text {rd }}$ order interaction model is only $2.25 \%$ better than the additive model

\begin{tabular}{ll}
\hline Variable & $\begin{array}{l}\text { Relative } \\
\text { impor- } \\
\text { tance }\end{array}$ \\
\hline Prefer strong leader & 100 \\
Prefer market over state & 84.81 \\
Oppose immigration & 62.55 \\
Oppose redistribution & 42.48 \\
Country group & 39.14 \\
Economic growth over environment & 37.59 \\
Satisfaction with the economy & 14.16 \\
Income level & 9.47 \\
Education level & 4.27
\end{tabular}

The most important factor score is set to 100

To take into account possible confounding factors, we compute a new dependent variable, $P_{i, c}$, as the absolute difference between the corruption perception of individual $i$ in country $c\left(C P_{i, c}\right)$ and the mean value of corruption perception in country $\left.c \overline{(C P}_{c}\right)$ :

$$
P_{i, c}=\operatorname{abs}\left(C P_{i, c}-\overline{C P}_{c}\right)
$$

$P_{i, c}$ represents a simple measure of the level of polarization ('extremism') of individual $i$ in country $c$. Being centered around the country average $P_{i, c}$, it embeds unobserved countrylevel effects and provides a better proxy of within-group variation at the individual level. Higher values of this measure are responses further away from one's country mean (either higher or lower), thus indicating higher levels of polarization.

To test H2 MARS model is used again with $P_{i, c}$ a as dependent variable and the same set of predictors as the ones used for testing H1. The models' order of interactions is assessed as in the previous case and, again, the additive model is chosen given that the marginal improvement of the goodness of fit of both the 2 nd and the $3 \mathrm{rd}$ order model is below $2.5 \%$ (Table 3 ). The most important predictors of corruption perception polarization are shown in Table 4, while the types of relationship for each single factor $B F$ s are displayed in Fig. 4. 


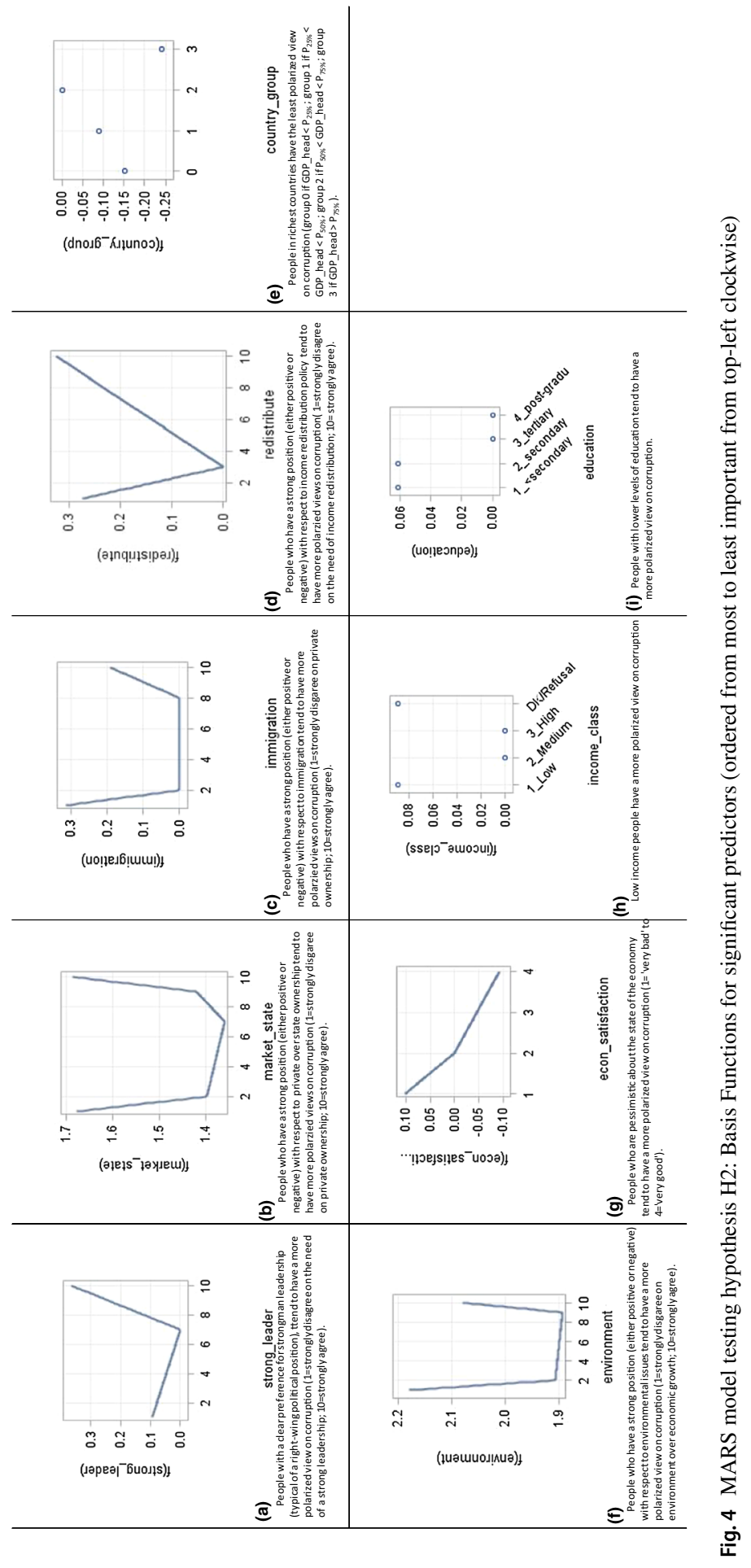


Table 5 Difference in difference estimates

\begin{tabular}{lll}
\hline & 1. Baseline & 2. With controls \\
\hline Traditional media & & \\
$\quad$ Government supporter & 3.79 & 4.18 \\
Opposition supporter & 3.95 & 4.30 \\
$\quad$ Diff & $0.16^{* * *}$ & $0.12^{* *}$ \\
$\quad p$-value & 0.01 & 0.01 \\
$\mathrm{n}$ & 42,194 & 42,088 \\
Social media & & \\
$\quad$ Government supporter & 4.31 & 4.31 \\
$\quad$ Opposition supporter & 4.76 & 4.69 \\
$\quad$ Diff & $0.45^{* * *}$ & $0.38^{* * *}$ \\
$\quad p$-value & 0.000 & 0.000 \\
$\mathrm{n}$ & 12,043 & 12,043 \\
Diff-in-Diff & $0.29 * * *$ & $0.26^{* * *}$ \\
st. error & 0.077 & 0.063 \\
$p$-value & 0.000 & 0.000 \\
\hline
\end{tabular}

$\mathrm{n}=54,234$. Means and standard errors calculated using linear regression, all figures rounded. Corruption variables range from 1 to 10 , with higher values $=$ greater perceived corruption. Difference in difference calculates the difference in corruption perceptions of the 'control' (other media) and 'treated' (social) media users among opposition and government supporters. Baseline include only the main variables, while the 2nd model includes age, gender, education, income population, political values, economic satisfaction, public service contact, unemployment and country fixed effects

Survey design and population weights included $* * * \mathrm{p}<0.01$; $* * \mathrm{p}<0.05 ; * \mathrm{p}<0.1$

When accounting for confounding factors, the effect of media on corruption polarization becomes negligible, indicating that no robust, statistical evidence supports $\mathrm{H} 2$. The effect of political attitudes is strong enough to nullify the effect of social media suggested by the simple, bivariate analysis. 'Extremists' on issues like the need of a strong leadership, economic markets, immigration, income redistribution and environment tend to have the most polarized views on corruption. Interestingly, almost all the Basis Functions $B F$ s estimated by MARS in this case are U-shaped (Fig. 4), meaning that people who identify on the far left or right of various political issues also tend to have more extreme perceptions of corruption relative to the mean of their country. This is due to the absolute value transformation of the dependent variable adopted in testing $\mathrm{H} 2$, as the focus is, in this case, on polarization of corruption perception rather than the levels themselves.

When accounting for control variables the effect of media becomes negligible. Yet, what if we select a societal cleavage around which perceptions are more or less polarized? As the design of this study is comparative and includes 21 countries with various political cultures and societal cleavages, admittedly many potentially interesting group-divisions could be driving greater polarization among social media consumers. One cleavage that would seem quite relevant across a diverse sample partisan divisions between government and opposition supporters (Anderson and Tverdova 2003; Bauhr and Charron 2018), spelled out in H3. To identify whether the gap in corruption perceptions increases between government 


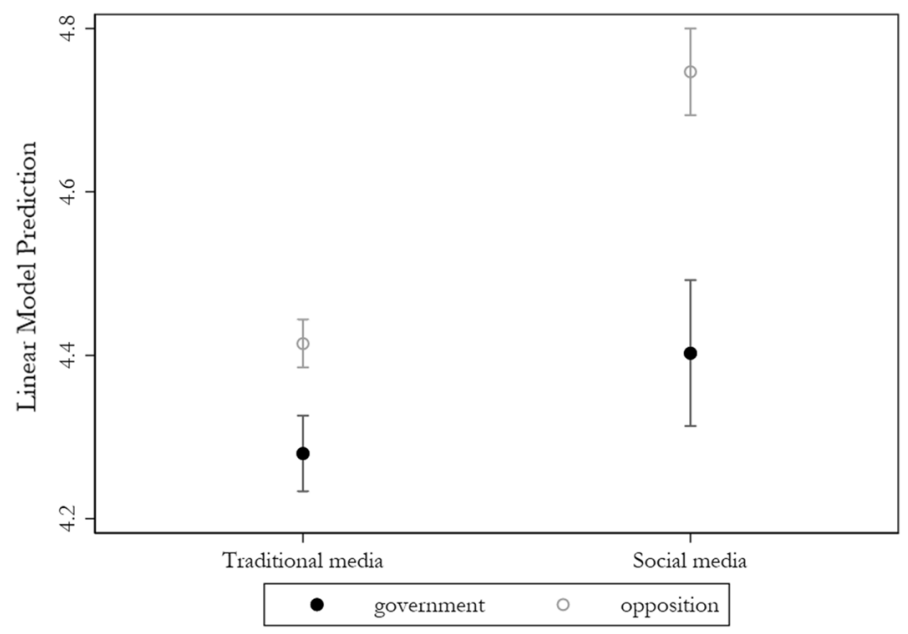

Fig. 5 Estimated effect of social media on corruption perceived by opposition and government supporters (with control factors). Note: average predictions of each dependent variable from OLS regression with $95 \%$ confidence intervals. All models include all control variables from Fig. 2 (not shown), country fixed effects, design weights and robust standard errors

and opposition supporters who consume social media as opposed to those who get news from another source, a simple difference in difference (DD) estimation was calculated in order to compare the estimated levels of corruption perception between government and opposition supporters based on their media source. ${ }^{7}$ Results are shown in Table 5.

We find the DD statistics significant in both cases that is to say, that the gap in the perception of corruption between opposition and government supporters is larger among social media than traditional media users. These bivariate results are of course subject to change once potentially confounding effects are added. We thus specify a full model with control variables $\left(\varphi_{i j}\right)$ to account for these potentially confounding effects, which are those factors included in the models to test $\mathrm{H} 1$ and $\mathrm{H} 2$ in model 2 in Table 5. The model is specified as such:

$$
C P_{i j}=\alpha_{j}+\beta 1\left(\text { socialmedia }_{i j}\right)+\beta 2\left(\text { opposition }_{i j}\right)+\beta 3\left(\text { socmedia }^{*} \text { opposition }\right)_{i j}+\varphi_{i j}(\text { controls })+\varepsilon_{i j}
$$

where $C P_{i j}$ are the corruption perceptions for individual $i$ in country $j$. In this model, the key variable of interest is the interaction parameter $\beta 3$ that serves as a difference in difference estimator to test the hypothesis on social media leading to greater levels of polarization of corruption perception between government and opposition supporters. As we are interested in obtaining point estimates for the four groups compared, in this case we estimate the model using a simple parametric approach, linear regression, summarized in Fig. 5 for the most significant variables. ${ }^{8}$

In Fig. 5, we observe the marginal effects of opposition support $(\beta 1)$ on corruption perceptions is shown over media source $(\beta 2)$, along with the interaction effect $(\beta 3)$. The Figure demonstrates several interesting results. One, opposition supporters have higher

\footnotetext{
7 The results are robust to including the 'don't knows' into the opposition group as well.

${ }^{8}$ A table reporting the full results is reported in the Appendix Sect. 3.
} 
perceptions of corruption irrespective of media, yet the estimated difference within the social media group more than doubles in each case. Remarkably, in the full model with controls (model 2, Table 5) the gap in perceptions of corruption is roughly three-fold larger among social media consumers (0.38) compared with traditional ones $(0.12)$, all the other controlling factors being equal; a difference that is equivalent to a $10 \%$ standard deviation increase in the dependent variable. Finally, it is interesting to note that differences in perception are negligible when comparing government supporters of social media with opposition supporters of traditional media.

\section{Discussion}

Perceptions of corruption are a critical part of citizens assessments of the system in which they live. A social system that is perceived as corrupt suggests a perceived lack of fairness, opportunities, and individual empowerment that generally have a negative impact on a whole host of important outcomes for society, such as voting, active citizenship, innovation, entrepreneurship and even overall happiness and life satisfaction (Helliwell 2003; Maciel and de Sousa 2018). Therefore, understanding what determines corruption perceptions (not simply experiences with corruption) is highly relevant for scholars and policymakers alike.

This study investigated the extent to which various sources of media have systematic effects on corruption perceptions in 21 European democracies. Using newly collected data from the European Quality of Government survey (Charron et al. 2019) and both parametric and non-parametric estimation, the results show that citizens who mainly obtain their news information from social media have higher perceptions of corruption than citizens who obtain news from more traditional sources, such as newspapers, radio and TV. While other factors are also important determinants of the variability in corruption perception, we find that there is an independent effect of social media. Compared with consumers of traditional media sources, we find consistent and robust support for our first research hypothesis, namely that social media consumption, on average, increases corruption perception levels.

We also analyzed the polarization of corruption perceptions and found that while the bivariate effects of social media are consistent with our second hypothesis that polarized attitude towards corruption is also driven by the use of social media, when including control variables the effects of media become negligible. Political attitudes have a stronger effect than the preferred type of media. However, when testing the third and last research hypothesis that imposes a particular cleavage on people's views, a greater polarization of perceptions is apparent between partisan supporters of government political parties and supporters of opposition parties among social media users. Results demonstrate that while opposition supporters have as expected higher levels of corruption perception, this effect is multiplied when they are primarily social media consumers. The mechanism posited in the theoretical section suggests that this is due to the combination between two factors. First, there are fewer establishment 'gatekeepers' in social media and thus news can be presented in a more extreme and sensational way also to attract more clicks, a need that more traditional media do not have. Second, low barriers to entry costs for social media allow for many news 
providers to emerge, find niche audiences, and better match the preferences of consumers. Those that support (oppose) the sitting government can more easily find friendly (hostile) news about political activity in one's country, leading to greater polarization of perceptions.

The findings here have several implications. One, if, as current trends suggest, social media consumption continues to increase, then this may increase polarization among the electorate regarding assessment of political institutions and trust in the system. This is clearly concerning. Two, this has implications for scholars measuring corruption. As it is commonplace to rely on perceptions to proxy for a country's level of corruption, this study reinforces previous findings that partisanship plays a key role in citizen assessment, and that this effect is only amplified among social media followers. Thus, surveys should account for these factors in future waves.

A main caveat of this study is the unavailability of time-series data at this point that impedes us to show how changes in media source consumption affect changes in perceptions of corruption within individuals that would give a stronger evidence to our findings. Further, we do note the that perceptions of corruption are not interchangeable proxies for 'actual' corruption levels, and that simply because perception among certain groups are high, does not necessarily translate into higher levels of actual corruption levels. However, employing a cross-section of individuals from 21 countries allows us to make a first step in better understanding this relationship empirically and hopefully leads to more research on this topic. In sum, the results do speak to many ongoing debates about the effects of social media on politics in democratic countries. With more and more citizens obtaining information from social media, the results suggest that the impact it has on people's opinions and lives is likely to get higher, not lower.

Funding Open access funding provided by University of Gothenburg.

Open Access This article is licensed under a Creative Commons Attribution 4.0 International License, which permits use, sharing, adaptation, distribution and reproduction in any medium or format, as long as you give appropriate credit to the original author(s) and the source, provide a link to the Creative Commons licence, and indicate if changes were made. The images or other third party material in this article are included in the article's Creative Commons licence, unless indicated otherwise in a credit line to the material. If material is not included in the article's Creative Commons licence and your intended use is not permitted by statutory regulation or exceeds the permitted use, you will need to obtain permission directly from the copyright holder. To view a copy of this licence, visit http://creativecommons.org/licenses/by/4.0/.

\section{Appendix}

\section{Section 1: Basics of MARS Modelling}

The MARS model explaining the dependent $f(\mathbf{x}, \boldsymbol{\tau})$ is a linear combination of piece-wise linear functions called basis (BFs) and their interactions (Friedman 1991; De Veaux et al 1993):

$$
f(x, \boldsymbol{\tau})=\beta_{0}+\sum_{m=1}^{M} \beta_{m} \varphi_{m}(x, \boldsymbol{\tau})
$$

where each $\varphi_{m}(x, \tau)$ is a $B F$ or, in the case of higher-order interactive models, a product of $B F_{\mathrm{s}}$ involving different explanatory factors $x_{i}$ to include interactions. Model parameters $\beta_{m}$ are estimated using the least squares method. A basis function is piece-wise linear transformations of the predictors $\mathbf{x}=\left\{x_{1}, x_{2} \ldots x_{n}\right\}$ defined as: 


$$
B F\left(x_{i}, \tau_{i}\right)=\max \left\{0, x_{i}-\tau_{i}\right\}+\left\{0, \tau_{i}-x_{i}\right\}
$$

where $\tau_{i}$ is an inflection point along the range of a given predictor $x_{i}$, the 'knot' of the basis splitting predictor $x_{i}$ into 2 groups. Basis functions are not pre-defined by the analyst but are rather estimated by the algorithm as the 'best possible functions' to express the dependent as a linear combination of $B F \mathrm{~s}$ (Eq. 1). These optimal functions can be visualized for each single predictor and provide useful insights on the type of relationship between the predictors and the dependent variable, as it is illustrated in this case for corruption perception and polarization. The effect of individual explanatory factors on the dependent variable can be visualized, enabling local interpretation of the underlying model. MARS also reports the explanatory variables by order of importance in terms of variation explained on the basis of a cross-validation criterion whereby the model goodness of fit is computed with and without each predictor.

\section{Section 2: Further Survey and Data Information}

\section{Background on Survey}

The field work began during the month of May, 2017 and were conducted in the local majority language in each country/region. The results were returned to the Quality of Government Institute in August, 2017.

The E.U. regional survey was undertaken by Efficience 3 (E3), a French marketresearch, Survey Company specializing in public opinion throughout Europe for researchers, politicians and advertising firms. E3 has also conducted the 2010 and 2013 rounds of the EQI and were thus familiar with the question format and goals of the survey. E3 conducted the interviews themselves in several countries and used sub-contracting partners in others. ${ }^{9}$ The respondents, from 18 years of age or older, were contacted randomly via telephone in the local language. Telephone interviews were conducted via both landlines and mobile phones, with both methods being used in most countries. Decisions about whether to contact residents more often via land or mobile lines was based on local expertise of market research firms in each country. For purposes of regional placement, respondents were asked the post code of their address to verify the area/region of residence if mobile phones were used.

Ideally, a survey would be a mirror image of actual societal demographics gender, income, education, rural-urban, ethnicity, etc. However, we are not privy to exact demographic distributions; in particular at the regional level in most cases, thus imposing artificial demographic lines might lead to even more problems than benefits. We thus sought the next best solution. Based on their expert advice, to achieve a random sample, we used what was known in survey-research as the 'next birthday method'. The next birthday method is an alternative to the so-called quotas method. When using the quota method for instance, one obtains a (near) perfectly representative sample e.g. a near exact proportion of the amount of men, women, certain minority groups, people of a certain age, income, etc. However, as one searches for certain demographics within the population, one might end up with only 'available' respondents, or those that are more

\footnotetext{
${ }^{9}$ https://www.efficience3.com/en/accueil/index.html. For names of the specific firms to which Efficience 3 sub-contracted in individual countries, please write cati@efficience3.com.
} 
'eager' to respond to surveys, which can lead to less variation in the responses, or even bias in the results. The 'next-birthday' method, which simply requires the interviewer to ask the person who answers the phone who in their household will have the next birthday, still obtains a reasonably representative sample of the population. The interviewer must take the person who has the next coming birthday in the household (if this person is not available, the interviewer makes an appointment), thus not relying on whomever might simply be available to respond in the household. So, where the quota method is stronger in terms of a more even demographic spread in the sample, the next-birthday method is stronger at ensuring a better range of opinion. The next-birthday method was thus chosen because we felt that what we might have lost in demographic representation in the sample would be made up for by a better distribution of opinion. In attempt to compensate for some key demographic over/under-representation, E3 provides weights based on age and gender for each region, comparing the sample drawn to actual demographic statistics from Eurostat. In the end, we find variation in response and refusal rates by country, which could have to do with many factors including the sensitivity of one of the primary the topics at hand corruption.

\section{Further Survey Questions Included as Non-Demographic Control Variables}

1 Political values (all have been re-coded so that higher values = more conservative/TAN) 'We'd like to ask you about your views on some issues in the next few questions. Please rate how strongly you agree with the following statements, with ' 1 ' being strongly disagree, and ' 10 ' being strongly agree."

a You prefer private ownership of business and industry over state ownership in most cases

b The government in (COUNTRY) should take measures to reduce differences in peoples' income.

c Protecting the environment should always take priority, even at the cost of economic growth

d immigrants contribute a lot to (COUNTRY)

e We need a strong leader with the willingness to punish those who don't behave properly.

2 Economic perceptions

How would you judge the current state of the economy in (COUNTRY)? 


\begin{tabular}{ll}
\hline 1 & Very good \\
2 & Somewhat good \\
3 & Somewhat bad \\
4 & Very bad \\
99 & (Don't know/Refused)
\end{tabular}

See Table 6

Table 6 Summary statistics

\begin{tabular}{llllll}
\hline Variable & Obs & Mean & Std. Dev & Min & Max \\
\hline Corruption perceptions index & 77,966 & 4.417 & 2.701 & 1 & 10 \\
Corruption perceptions index (alt) & 77,966 & 4.244 & 2.282 & 1 & 10 \\
Extreme_corruption perceptions & 77,966 & 2.048 & 1.348 & 0.005 & 7.849 \\
Social media & 77,966 & 0.236 & 0.425 & 0 & 1 \\
opposition & 54,237 & 0.605 & 0.489 & 0 & 1 \\
Social media* opposition & 54,237 & 0.142 & 0.350 & 0 & 1 \\
female & 77,966 & 0.514 & 0.500 & 0 & 1 \\
Age & 77,966 & 2.555 & 1.023 & 1 & 4 \\
Income: low & 77,966 & 0.307 & 0.461 & 0 & 1 \\
Income: medium & 77,966 & 0.301 & 0.459 & 0 & 1 \\
Income: high & 77,966 & 0.310 & 0.462 & 0 & 1 \\
Income: dk & 77,966 & 0.082 & 0.275 & 0 & 1 \\
University & 77,966 & 0.423 & 0.494 & 0 & 1 \\
Urban & 77,966 & 0.065 & 0.247 & 0 & 1 \\
Unemployed & 77,966 & 0.059 & 0.236 & 0 & 1 \\
Econsat: very satisfied & 77,966 & 0.080 & 0.271 & 0 & 1 \\
Econsat: somewhat satisfied & 77,966 & 0.485 & 0.500 & 0 & 1 \\
Econsat: somewhat disstisfied & 77,966 & 0.274 & 0.446 & 0 & 1 \\
Econsat: very dissatisfied & 77,966 & 0.157 & 0.364 & 0 & 1 \\
Econsat: dk & 77,966 & 0.004 & 0.066 & 0 & 1 \\
Market_state & 76,886 & 6.060 & 2.761 & 1 & 10 \\
Oppose redistribution & 77,612 & 3.712 & 2.795 & 1 & 10 \\
Growth v environment & 77,718 & 3.598 & 2.487 & 1 & 10 \\
Immigration & 77,340 & 5.440 & 2.863 & 1 & 10 \\
Strong_leader & 77,412 & 6.988 & 2.952 & 1 & 10 \\
\hline
\end{tabular}




\section{Section 3: Further Information from the Main Analyses}

See Table 7

Table 7 Test of interaction (H3) full results

\begin{tabular}{lll}
\hline & 1. Baseline & 2. Full model \\
\hline Social media & $0.147^{* * *}(0.051)$ & $0.123^{* *}(0.051)$ \\
$(0.051)$ & & \\
1.opposition & $0.282^{* * *}(0.028)$ & $0.135^{* * *}(0.028)$ \\
Soc. media 4 opp & $0.232^{* * *}(0.059)$ & $0.210^{* * *}(0.058)$ \\
Female & & $-0.053^{* *}(0.022)$ \\
Age & & $-0.001(0.011)$ \\
Income: medium & & $-0.193^{* * *}(0.029)$ \\
Income: high & & $-0.088^{* * *}(0.030)$ \\
Income: d/k & & $-0.180^{* * *}(0.046)$ \\
University & & $-0.270^{* * *}(0.024)$ \\
Urban & & $0.250^{* * *}(0.042)$ \\
Support redistribution & & $-0.793^{* * *}(0.043)$ \\
Oppose immigration & & $0.594^{* * *}(0.047)$ \\
Public sec. exp & & $0.025(0.032)$ \\
Econ: very sat & & $-1.246^{* * *}(0.057)$ \\
Econ: somewhat sat & & $-0.965^{* * *}(0.042)$ \\
Econ: somewhat dissat & & $-0.387^{* * *}(0.040)$ \\
Unemployed & & $0.136^{* * *}(0.051)$ \\
cons & $4.304^{* * *}(0.040)$ & $5.160^{* * *}(0.078)$ \\
Obs & 77,684 & 76,808 \\
R-squared & 0.151 & 0.183 \\
\hline
\end{tabular}

Robust standard errors are in parenthesis. Models include country fixed effects (not shown) and design weights. Reference category for income is 'low' and reference category for economic satisfaction is 'very dissatisfied'. 'Don't know' ('d/k') answers also included as a dummy variable

$* * * p<0.01, * * p<0.05, * p<0.1$

\section{Section 4: Results with Alternative Dependent Variable}

\section{Alternative Measure of Corruption Perceptions}

To check the robustness of our findings, we incorporate additional survey items on corruption perceptions pertaining to specific service areas in addition to our two main questions describe in the main text. The items in total are:

In this survey we define corruption to mean the abuse of entrusted public power for private gain. This abuse could be by any public employee or politician and the private gain might include money, gifts or other benefits. B With this in mind, please respond to the following five questions on corruption with a scale of $0-10$, with ' 0 ' being "strongly disagree" and ' 10 ' being strongly agree. 
Corruption is prevalent in my area's local public school system.

Corruption is prevalent in the public health care system in my area.

Corruption is prevalent in the police force in my area.

Corruption is NOT present in elections in my area.

I trust the information provided by the local mass media in reporting on matters of politics and public services in my area.

The Cronbach Alpha measure of reliability is 0.86 and a principle component factor analysis reveals that the 5 items load onto a single factor (Eigenvalue $=3.17$, proportion variance $=0.63$ ). Moreover, the PCF test shows roughly equal variance explained by the 5 items, and thus we aggregate these 5 items into a single index with equal weighting.

See Tables 8 and 9

Table 8 Test for difference in means and variances of corruption perception by media source with alternate corruption index

Table 9 Difference in difference estimates with alternate corruption index (alternative Table 4)

\begin{tabular}{llll}
\hline & $\begin{array}{l}\text { Traditional } \\
\text { media }\end{array}$ & Social media & Difference $(p$-value) \\
\hline Mean & 4.17 & 4.48 & $0.31(0.000)$ \\
Variance & 5.13 & 5.36 & $0.23(0.000)$ \\
\hline
\end{tabular}

Sample-wise unweighted averages, $p$-values report one-tailed tests

\begin{tabular}{lll}
\hline & 1. Baseline & 2. With controls \\
\hline Traditional media & & \\
Government supporter & 3.69 & 4.01 \\
Opposition supporter & 3.84 & 4.15 \\
Diff & $0.15^{* * *}$ & $0.14 * *$ \\
$p$-value & 0.003 & 0.01 \\
n & 40,967 & 42,088 \\
Social media & & \\
Government supporter & 4.19 & 4.14 \\
Opposition supporter & 4.55 & 4.46 \\
Diff & $0.36^{* * *}$ & $0.42^{* * *}$ \\
$p$-value & 0.000 & 0.000 \\
$\mathrm{n}$ & 11,779 & 12,043 \\
Diff-in-Diff & $0.21^{* * *}$ & $0.31 * * *$ \\
st. error & 0.066 & 0.053 \\
$p$-value & 0.003 & 0.000 \\
\hline
\end{tabular}

$\mathrm{n}=52,746$ in model 1 and 52,308 in model 2. Means and standard errors calculated using linear regression, all figures rounded. Corruption variables range from 1 to 10 , with higher values = greater perceived corruption. Difference in difference calculates the difference in corruption perceptions of the 'control' (other media) and 'treated' (social) media users among opposition and government supporters. Baseline include only the main variables, while the 2 nd model includes age, gender, education, income population, political values, economic satisfaction, public service contact, unemployment and country fixed effects

Survey design and population weights included ${ }^{* * *} p<0.01$; $* * p<0.05 ; * p<0.1$ 


\section{References}

Aarts, K., Fladmoe, A., \& Strömbäck, J. (2012). Media, political trust, and political knowledge. How media inform democracy: A comparative approach, 98-118.

Abramowitz, A. I., \& Saunders, K. L. (2008). Is polarization a myth? The Journal of Politics, 70(2), 542-555.

Agerberg, M. (2017). Failed expectations: Quality of government and support for populist parties in Europe. European Journal of Political Research, 56(3), 578-600.

Agerberg, M. (2020). "Corrupted estimates? Response bias in citizen surveys on corruption. Political Behavior. https://doi.org/10.1007/s11109-020-09630-5

Ananny, M. (2014). Networked press freedom and social media: Tracing historical and contemporary forces in press-public relations. Journal of Computer-Mediated Communication, 19(4), 938-956.

Anderson, C. J., \& Tverdova, Y. V. (2003). Corruption, political allegiances, and attitudes toward government in contemporary democracies. American Journal of Political Science, 47(1), 91-109.

Andersen, T. B., Bentzen, J., Dalgaard, C. J., \& Selaya, P. (2011). Does the Internet reduce corruption? Evidence from US states and across countries. The World Bank Economic Review, 25(3), 387-417.

Annoni, P., \& Catalina-Rubianes, A. (2016). Tree-based approaches for understanding growth patterns in the European regions. Region The Journal of ERSA, 3, 23-45.

Annoni, P., \& Charron, N. (2019). Measurement assessment in cross-country comparative analysis: Rasch modelling on a measure of institutional quality. Social Indicators Research, 141, 31-60.

Bartels, L. M. (2002). Beyond the running tally: Partisan bias in political perceptions. Political behavior, 24(2), 117-150.

Bauhr, M. (2017). Need or greed? Conditions for collective action against corruption. Governance, 30(4), $561-581$.

Bauhr, M., \& Charron, N. (2018). Insider or outsider? Grand corruption and electoral accountability. Comparative Political Studies, 51(4), 415-446.

Baum, M. A. (2003). Soft news and political knowledge: Evidence of absence or absence of evidence? Political Communication, 20(2), 173-190.

Barberá, P. (2015). Birds of the same feather tweet together: Bayesian ideal point estimation using Twitter data. Political Analysis, 23(1), 76-91.

Bennett, W. L., \& Iyengar, S. (2008). A new era of minimal effects? The changing foundations of political communication. Journal of communication, 58(4), 707-731.

Brunetti, A., \& Weder, B. (2003). A free press is bad news for corruption. Journal of Public economics, 87(7), 1801-1824.

Blais, A., Gidengil, E., \& Kilibarda, A. (2017). Partisanship, information, and perceptions of government corruption. International Journal of Public Opinion Research, 29(1), 95-110.

Campante, F. R., \& Hojman, D. A. (2013). Media and polarization: Evidence from the introduction of broadcast TV in the United States. Journal of Public Economics, 100, 79-92.

Campbell, A., Converse, P. E., Miller, W. E., \& Donald, E. (1966). Stokes. 1960. The american voter, 8.

Ceron, A. (2015). Internet, news, and political trust: The difference between social media and online media outlets. Journal of Computer-Mediated Communication, 20(5), 487-503.

Charron, N. (2016). Do corruption measures have a perception problem? Assessing the relationship between experiences and perceptions of corruption among citizens and experts. European Political Science Review, $8(1), 147-171$.

Charron, N., \& Bågenholm, A. (2016). Ideology, party systems and corruption voting in European democracies. Electoral Studies, 41, 35-49.

Charron, N., Dijkstra, L., \& Lapuente, V. (2015). Mapping the regional divide in Europe: A measure for assessing quality of government in 206 European regions. Social Indicators Research, 122(2), 315-346.

Charron, N., Lapuente, V., \& Annoni, P. (2019). Measuring quality of government in EU regions across space and time. Papers in Regional Science, 98(5), 1925-1953.

Conover, M., Ratkiewicz, J., Francisco, M. R., Gonçalves, B., Menczer, F., \& Flammini, A. (2011). Political polarization on twitter. International Conference on Weblogs and Social Media, 133, 89-96.

Conover, M. D., Gonçalves, B., Flammini, A., \& Menczer, F. (2012). Partisan asymmetries in online political activity. EPJ Data Science, 1(1), 6.

Costas-Pérez, E., Solé-Ollé, A., \& Sorribas-Navarro, P. (2012). Corruption scandals, voter information, and accountability. European Journal of Political Economy, 28(4), 469-484.

d'Agostino, G., \& Pieroni, L. (2019). Modelling corruption perceptions: Evidence from Eastern Europe and Central Asian countries. Social Indicators Research, 142(1), 311-341.

Dahlberg, S., \& Solevid, M. (2016). Does corruption suppress voter turnout? Journal of Elections, Public Opinion and Parties, 26(4), 489-510. 
Deichmann, J., Eshghi, A., Haughton, D., Sayek, S., \& Teebagy, N. (2002). Application of multiple adaptive regression splines (MARS) in direct response modeling. Journal of Interactive Marketing, 16, 15-27.

De Veaux, R., Psichogios, D., \& Ungar, L. (1993). A comparison of two nonparametric estimation schemes: MARS and neural networks. Computers in Chemical Engineering, 17, 819-837.

DiMaggio, P., Evans, J., \& Bryson, B. (1996). Have American's social attitudes become more polarized? American journal of Sociology, 102(3), 690-755.

Donchev, D., \& Ujhelyi, G. (2014). What do corruption indices measure? Economics and Politics, 26(2), 309-331.

Ferraz, C., \& Finan, F. (2008). Exposing corrupt politicians: The effects of Brazil's publicly released audits on electoral outcomes. The Quarterly Journal of Economics, 123(2), 703-745.

Feezell, J. T. (2018). Agenda setting through social media: The importance of incidental news exposure and social filtering in the digital Era. Political Research Quarterly, 71(2), 482-494.

Freille, S., Haque, M. E., \& Kneller, R. (2007). A contribution to the empirics of press freedom and corruption. European Journal of Political Economy, 23(4), 838-862.

Friedman, J. (1991). Multivariate Adaptive regression Splines. Annals of Statistics, 19, 1-141.

Fukuyama, F. (2018). Against identity politics: The new Tribalism and the Crisis of democracy. Foreign Affairs, 97, 90.

Gil de Zúñiga, H., Jung, N., \& Valenzuela, S. (2012). Social media use for news and individuals' social capital, civic engagement and political participation. Journal of Computer-Mediated Communication, 17(3), 319-336.

Goel, R. K., Nelson, M. A., \& Naretta, M. A. (2012). The internet as an indicator of corruption awareness. European Journal of Political Economy, 28(1), 64-75.

Helliwell, J. F. (2003). How's life? Combining individual and national variables to explain subjective wellbeing. Economic modelling, 20(2), 331-360.

Hermida, A., Lewis, S. C., \& Zamith, R. (2014). Sourcing the Arab spring: A case study of Andy Carvin's sources on Twitter during the Tunisian and Egyptian revolutions. Journal of Computer-Mediated Communication, 19(3), 479-499.

Heywood, P. M., \& Rose, J. (2014). “Close but no Cigar”: The measurement of corruption. Journal of Public Policy, 34(3), 507-529.

Hindman, D. B. (2009). Mass media flow and differential distribution of politically disputed beliefs: The belief gap hypothesis. Journalism and Mass Communication Quarterly, 86(4), 790-808.

Huckfeldt, R. R., \& Sprague, J. (1995). Citizens, politics and social communication: Information and influence in an election campaign. Cambridge: Cambridge University Press.

Inglehart, R., \& Welzel, C. (2010). Changing mass priorities: The link between modernization and democracy. Perspectives on Politics, 8(2), 551-567.

Iversen, T., \& Soskice, D. (2015). Information, inequality, and mass polarization: Ideology in advanced democracies. Comparative Political Studies, 48(13), 1781-1813.

Jerit, J., \& Barabas, J. (2012). Partisan perceptual bias and the information environment. The Journal of Politics, 74(3), 672-684.

Kostadinova, T. (2009). Abstain or rebel: Corruption perceptions and voting in East European elections. Politics and Policy, 37(4), 691-714.

Landenna, G. (1994) Fondamenti di Statistica Descrittiva. Il Mulino, (320) EAN: 9788815045607; ISBN: 8815045600 .

Lewis, M. (2012). Social cognition and the acquisition of self. Berlin: Springer.

Lindstedt, C., \& Naurin, D. (2010). Transparency is not enough: Making transparency effective in reducing corruption. International political science review, 31(3), 301-322.

Maciel, G. G., \& de Sousa, L. (2018). Legal corruption and dissatisfaction with democracy in the European Union. Social Indicators Research, 140(2), 653-674.

Mishler, W., \& Rose, R. (2008). Seeing is not always believing: Measuring corruption perceptions and experiences. In Elections, public opinion and parties 2008 annual conference (pp. 12-14).

Morris, E. K., et al. (2014). Choosing and using diversity indices: Insights for ecological applications from the German Biodiversity Exploratories. Ecology and Evolution, 4(18), 3514-3524.

Mutz, D. C. (2001). Facilitating communication across lines of political difference: The role of mass media. American Political Science Review, 95(1), 97-114.

Nie, N. H., Miller, D. W., III., Golde, S., Butler, D. M., \& Winneg, K. (2010). The world wide web and the US political news market. American Journal of Political Science, 54(2), 428-439.

Norris, P. (2000). A virtuous circle: Political communications in postindustrial societies. Cambridge: Cambridge University Press.

Norris, P. (2011). Democratic deficit: Critical citizens revisited. Cambridge: Cambridge University Press. 
Olken, B. A. (2009). Corruption perceptions versus corruption reality. Journal of Public Economics, 93(7-8), 950-964.

O’reilly, T. (2005). Web 2.0: compact definition. pp 137-158.

Oser, J., Hooghe, M., \& Marien, S. (2013). Is online participation distinct from offline participation? A latent class analysis of participation types and their stratification. Political Research Quarterly, 66(1), 91-101.

Pellegata, A., \& Memoli, V. (2016). Can corruption erode confidence in political institutions among European countries? Comparing the effects of different measures of perceived corruption. Social Indicators Research, 128(1), 391-412.

Prior, M. (2007). Post-broadcast democracy: How media choice increases inequality in political involvement and polarizes elections. Cambridge: Cambridge University Press.

Prior, M. (2013). Media and political polarization. Annual Review of Political Science, 16, 101-127.

Rose, R., \& Mishler, W. (2007). Explaining the gap between the experience and perception of corruption. Centre for the study of public policy, U. of aberdeen: Studies in public policy, (432).

Sharafutdinova, G. (2010). What explains corruption perceptions? The dark side of political competition in Russia's regions. Comparative Politics, 42(2), 147-166.

Valkenburg, P. M., Peter, J., \& Walther, J. B. (2016). Media effects: Theory and research. Annual Review of Psychology, 67, 315-338.

Valenzuela, S., Park, N., \& Kee, K. F. (2009). Is there social capital in a social network site?: Facebook use and college students' life satisfaction, trust, and participation. Journal of Computer-Mediated Communication, 14(4), 875-901.

Varian, H. R. (2014). Big data: New tricks for econometrics. Journal of Economic Perspectives, 28, 3-28.

Zhang, W., \& Goh, A. T. C. (2016). Multivariate adaptive regression splines and neural network models for prediction of pile drivability. Geoscience Frontiers, 7, 45-52.

Zhu, J., Lu, J., \& Shi, T. (2013). When grapevine news meets mass media: Different information sources and popular perceptions of government corruption in mainland China. Comparative Political Studies, 46(8), 920-946.

Publisher's Note Springer Nature remains neutral with regard to jurisdictional claims in published maps and institutional affiliations. 